\title{
The Protective Effect of Testosterone on Indomethacin Induced Gastric Ulcer in Female Sprague Dawley Rats
}

\author{
U. Akpamu, ${ }^{1,2}$ H. O. Otamere, ${ }^{2}$ I. O. Ernest-Nwoke, ${ }^{2}$ C. N. Ekhator, ${ }^{2}$ and U. C. Osifo ${ }^{2}$ \\ ${ }^{1}$ Department of Health Promotion and Education, Faculty of Public Health, University of Ibadan, Ibadan, Nigeria \\ ${ }^{2}$ Department of Physiology, Faculty of Basic Medical sciences, College of Medicine, Ambrose Alli University, Ekpoma, Edo State, Nigeria \\ Correspondence should be addressed to U. Akpamu; uwaifoha@yahoo.co.uk
}

Received 2 August 2016; Revised 28 September 2016; Accepted 23 October 2016

Academic Editor: Oscar González-Flores

Copyright (c) 2016 U. Akpamu et al. This is an open access article distributed under the Creative Commons Attribution License, which permits unrestricted use, distribution, and reproduction in any medium, provided the original work is properly cited.

\begin{abstract}
Gastric ulcer has shown association with changes in sex hormones, with impact exacerbated in males. Also, males are known to be more exposed to ulcer risk factors. This study investigates the effect of testosterone on indomethacin induced gastric ulcers in adult female rats. Eighteen female rats $(225 \pm 25 \mathrm{~g}$ body weight $)$ were randomly assigned to 3 groups under standard laboratory condition. After acclimatization, animals fasted for $40 \mathrm{hrs}$ but were given water ad libitum. Group A served as control while group B served as the ulcer control, in which ulcer was induced without treatment using indomethacin ( $40 \mathrm{mg} / \mathrm{kg}$ single orally dose). Group $\mathrm{C}$ was pretreated with testosterone $(1 \mathrm{mg} / \mathrm{kg} \mathrm{IM})$ eight hours before ulcer induction. Eight hours after ulcer induction, animals were sacrificed and the stomach was harvested for analysis. Results showed a significant reduction in mucus content in groups $\mathrm{C}$ $(0.79 \pm 0.11 \mathrm{~g})$ and $\mathrm{B}(0.87 \pm 0.02 \mathrm{~g})$ compared to A $(1.11 \pm 0.03 \mathrm{~g})$. Gastric mucus $\mathrm{pH}$ was significantly acidic in group B (4.40 \pm 0.55$)$ compared to $\mathrm{C}(5.20 \pm 0.45)$ and $\mathrm{A}(5.80 \pm 0.45)$. There was a significantly higher ulcer index in group B $(4.60 \pm 0.55 \mathrm{~mm})$ compared to $\mathrm{C}(3.60 \pm 0.89 \mathrm{~mm})$ and testosterone pretreatment resulted in a $21.74 \%$ ulcer inhibition. Although weak, the findings suggest that testosterone might protect the gastric mucosa against NSAIDs in females.
\end{abstract}

\section{Introduction}

Nonsteroidal anti-inflammatory drugs (NSAIDs) have long been implicated in ulcer aetiology and employed in several animal studies for gastric ulcers induction [1-4]. Indomethacin is a commonly used type of NSAIDs in animal experiment whose proposed mechanism of stomach damage has been reported to be through local/topical and systemic actions. The topical mechanism involves those of acidic nature which directly kill epithelial cells $[5,6]$. In the topical action, gastric ulcerogenic action of NSAIDs is reported to be due to their local inhibitory effect on gastric prostaglandin E2 (PGE2) and prostaglandin I2 (PGI2) that are the main inhibitors of gastric acid secretion [7] as well as induction of osmotic lysis subsequent to trapping of charged NSAIDs with the epithelial cells [8] and death of the epithelial cell subsequent to uncoupling of oxidative phosphorylation [9]. Also, NSAIDs have been said to diminish the ability of Epithelial Growth Factor to promote epithelial repair, and thus inhibition of epithelial proliferation appears to involve a reduction of EGF binding to its receptor [10] and inhibition of EGF signalling pathways [11, 12].

The development of peptic ulcer has been said to be influenced by various aggressive and defensive factors [13-15], inadequate dietary habits, cigarette smoking, excessive ingestion of nonsteroidal anti-inflammatory agents, stress, hereditary predisposition, Helicobacter pylori infection $[1,3,16-$ 18], free radicals formation [19], and decreased prostaglandin synthesis [20]. Although several pharmaceutical products have been employed and have resulted in decreased rate of mortality and morbidity of gastric ulcers, none, however, is completely effective [21]. According to studies, the available drugs used for the treatment of gastric ulcers are not without adverse effects and limitations [22-25]. Thus, there is a growing interest in alternative therapies with promising outcomes and nontoxic effects to other organs or systems.

Interestingly, there has been an observation that "peptic ulcers occur more frequently among men than women at reproductive age" $[26,27]$. By implication, this gives rise to the question "could testosterone (a major androgen and male 
sex hormone) be responsible for this effect?" Nevertheless, males are known to be more exposed to stress, cigarette smoking, excessive ingestion of alcohol, and inadequate dietary habits, which are known to be implicated in the development of gastric ulcers. Hence, the assumption that testosterone could be responsible for the frequency of peptic ulcers among men than women at reproductive age is questionable. However, according to Kirsner [28], sex differences in peptic ulcer have not been adequately explained and it is presumably said that the greater exposure of men to environmental influences predisposing to ulcer and the development of ulcers in women subjected to comparable or similar tensions suggest the role of other factors.

Although existing facts suggest that gastric acid secretion, gastroduodenal mucosa integrity, and gastric ulcerations are associated with changes that occur within hormonal cycles, especially those related to sex hormones [26], the possible deleterious effects of the androgenic hormones remain to be investigated. The possible protective influence of female sex hormones thus far has not been established and the course of peptic ulcer in women during various phases of the reproductive period might be expected to provide information pertinent to this.

Considering that studies have reported antiulcer drugs side effects to include disturbance of plasma hormone levels [29-33] is an indication suggesting the relationship between hormonal difference and the development of gastric ulcers. Despite these facts that relate sex hormones and ulcer development, little literature exists regarding the effect of male sex hormone on ulcer prevention. This study investigates the protective effect of testosterone on indomethacin induced gastric ulcer in female rats.

\section{Materials and Methods}

2.1. Experimental Animals. Eighteen adult female rats of comparable weight $(225 \pm 25 \mathrm{~g})$ were obtained from the Animal House of Anthonio Research Centre and transported to the experiment site where they were housed in a wellventilated room under a 12/12 hours' light/dark cycle and fed with feed (Vital feed, Plateau State, Nigeria) and water ad libitum.

2.2. Drug of Study. Testosterone (testosterone propionate USP $25 \mathrm{mg}$ made in India by Laborate pharmaceutical) was purchased from a Pharmacy in Ekpoma, Nigeria.

2.3. Experimental Grouping. Following standard laboratory animal care, the rats were randomly divided to three groups ( $\mathrm{A}, \mathrm{B}$, and $\mathrm{C}$ ) of 6 rats each; group $\mathrm{A}$ served as the control, $\mathrm{B}$ as the ulcer control, and $\mathrm{C}$ as the test group.

2.4. Ulcer Induction. Ulcer was induced by a single oral dose of indomethacin $(40 \mathrm{mg} / \mathrm{kg} / \mathrm{bwt})$ as previously reported by Akpamu et al. [34].

2.5. Experimental Design. Following a 2-week period of acclimatization, animals in group A received no treatment (control). After 40 hours of fasting, animals in group B were given intramuscularly tween 80 and at the 48 th hour, they received orally indomethacin $(40 \mathrm{mg} / \mathrm{Kg})$. After 40 hours of fasting, animals in test group C were pretreated with $1 \mathrm{mg} / \mathrm{kg}$ IM testosterone [26]. Eight (8) hours later, ulcer was induced with indomethacin ( $40 \mathrm{mg} / \mathrm{kg}$ single dose orally). Eight (8) hours after the induction of ulcers in groups B and C, the animals were prepared for sample collection.

2.6. Sample Collection. At the end of the treatments, the rats in each group were sacrificed under mild chloroform anesthesia and the stomach was obtained following standard laboratory procedures as described by Abdulla et al. [35] and Ketuly et al. [36].

2.7. Sample Analysis. The stomach was opened along the greater curvature and the content emptied. It was then rinsed with saline water and gastric mucus was obtained by gentle scraping of the mucosa with a glass slide and then weighed using an electronic weighting balance.

Also, the acidity of gastric mucus was determined using litmus paper with colour indicator. Gastric mucosal lesions were then examined macroscopically using dissecting microscope for ulcer index analysis. Gross gastric lesions severity was measured as described by Wilhelmi and Menasse-Gdynia [37] using the 1 to 5 scoring system (severity factor $1=1$ or 2 minutes, sporadic, punctuate lesion; 2 = several small lesions; 3 = one extensive lesion or multiple moderate sized lesions; 4 = several large lesions; 5 = several large lesions with stomach perforation). The UI for each group was taken as the mean lesion score of all the rats in that group [35]. The percentage ulcer inhibition (\% UI) was calculated by the equation of Hano et al. [38].

$$
\begin{aligned}
\% \mathrm{UI}= & {\left[\frac{(\mathrm{UI} \text { of ulcer control }- \text { UI of treated })}{(\mathrm{UI} \text { of ulcer control })}\right] } \\
& \times 100 \% .
\end{aligned}
$$

2.8. Data Analysis. This was by the one-way analysis of variance (ANOVA) which was performed using SPSS version 17 software. The post hoc test carried out was LSD and the significance level was set at $p<0.05$.

\section{Results}

Ulcers of the gastric mucosa appear as inflammation and haemorrhagic lesions on the wall of the stomach. There was a significant reduction $(p<0.05 ; F=50.4117)$ in mucus content in groups $C(0.74 \pm 0.10 \mathrm{~g})$ and $\mathrm{B}(0.87 \pm 0.02 \mathrm{~g})$ compared to the control $(1.11 \pm 0.03 \mathrm{~g})$. Similarly, the mucus content of group B was significantly higher $(p<0.05)$ compared to group $\mathrm{C}$ (Figure 1). Gastric mucus $\mathrm{pH}$ was significantly acidic $(p<0.05 ; F=10.571)$ in group B $(4.40 \pm 0.55)$ compared to group $\mathrm{C}(5.20 \pm 0.45)$ and control $(5.80 \pm 0.45)$ (Figure 2). The results showed significantly higher $(p<0.05 ; F=79.818)$ ulcers index in group B $(4.60 \pm 0.55)$ compared to group C $(3.60 \pm 0.89)$. Pretreatment with testosterone resulted in a $21.74 \%$ ulcer inhibition in group C (Table 1). 


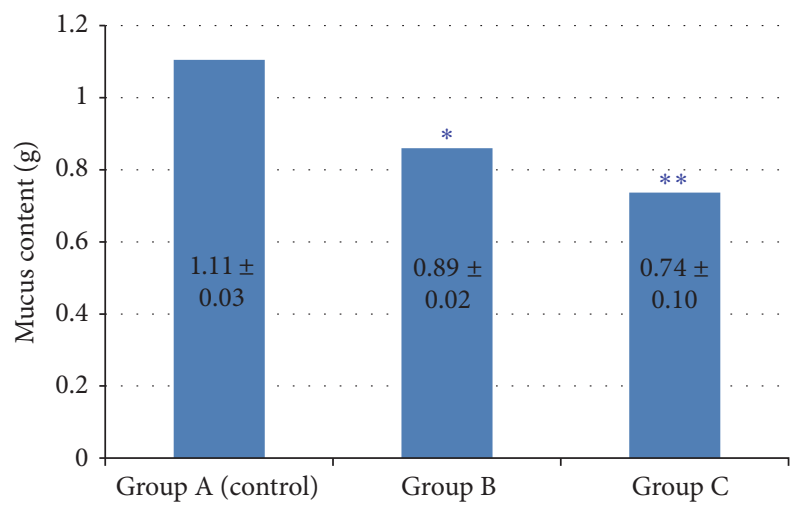

Figure 1: Mucus content (gram) of treatments and control. * denotes significant different compared to control and $* *$ compared to group B (test control) at the $p<0.05$ level $(n=6)$.

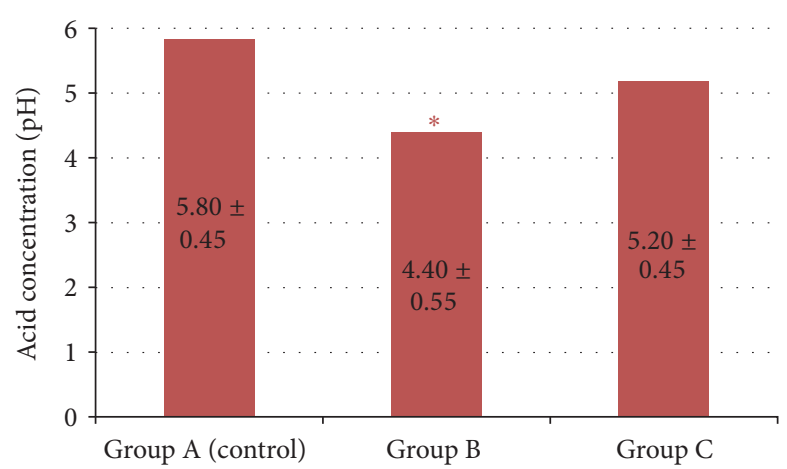

Figure 2: Acid concentration $(\mathrm{pH})$ of treatments and control. * denotes significant different compared to control at the $p<0.05$ level $(n=6)$.

\section{Discussion}

On the influence of testosterone treatments on indomethacin induced gastric ulcers in female rat, the present study showed testosterone pretreatment to significantly reduced mucus content (Figure 1) and nonsignificantly reduced gastric acidity (Figure 2) compared to group B; in which ulcer was induced without treatment. Also, pretreatment with testosterone was observed to result in a milder ulcer compared to that without treatment (group B; Table 1) and resulted in a $21.74 \%$ ulcer inhibition when compared to that in group B. These findings in the present study indicate that pretreatment with testosterone may be gastroprotective in female rats. Worrisome, however, is the significant reduction in gastric mucus production observed in the present study. Hence, the findings on the effect of testosterone in this study further support the hypothesis by El-Tawil [39] that sex hormones may act through potentiating the effect of other cofactors in inducing or modulating pathogenesis of gastrointestinal disorder.

Estrogens have been shown to inhibit gastric acid secretion in female human and animal studies [40-44]; the finding of this study on the effect of testosterone on gastric acidity showed that testosterone may neutralise gastric acidity induced by indomethacin, at least in female rat. This
TABLE 1: Evaluation of gastric ulcer index and inhibition by testosterone in indomethacin induced gastric ulcer in female rats treated with testosterone.

\begin{tabular}{lccc}
\hline Physical observations & $\begin{array}{c}\text { Group A } \\
\text { Control) } \\
(n=6)\end{array}$ & $\begin{array}{c}\text { Group B } \\
\text { (Ulcer control) } \\
(n=6)\end{array}$ & $\begin{array}{c}\text { Group C } \\
\text { Testosterone) } \\
(n=6)\end{array}$ \\
\hline Severity factor & - & $\mathrm{S}$ & $\mathrm{MS}$ \\
Ulcer index & $0^{\mathrm{a}}$ & $4.60 \pm 0.55^{\mathrm{b}}$ & $3.60 \pm 0.89^{\mathrm{c}}$ \\
$\%$ UI & $100^{\mathrm{b}}$ & $0^{\mathrm{b}}$ & $21.74^{\mathrm{c}}$ \\
\hline
\end{tabular}

Means in a row with different superscripts are significantly different at the $p<0.05$ level.

Key: $-=$ absent; $\mathrm{MS}=$ mildly severe; $\mathrm{S}=$ severe; $\% \mathrm{UI}=$ percentage ulcer inhibition.

estrogenic effect observed in human and animals [40-44] was exhibited by testosterone in female rats considering the similar and nonsignificant $(p<0.05)$ difference in gastric acid concentration between pretreatment with testosterone and control and the significant difference $(p>0.05)$ between pretreatment with testosterone and group $B$. This is in accordance with considering that it has been demonstrated that androstenedione and testosterone can be aromatized to estrone and estradiol [45-47]. Thus, the observed estrogenic effect by testosterone may be that testosterone was converted to estradiol by the enzyme aromatase. In another line of thought, testosterone may have similar effect of estrogen to bring about the increased mucus acidity in female observed in this study.

Considering the observed ulcer indices in the present study, pretreatment with testosterone was shown to be gastroprotective against indomethacin induced gastric ulcerations. Previous studies have shown the administration of testosterone receptor blockers (cyproterone acetate) to attenuated gastric haemorrhagic erosions in intact male rats following ethanol challenge [48, 49]. A study has previously reported that administration of testosterone in the presence of testes significantly protected intestinal tissue against postischemia/reperfusion mucosal injuries, while the opposite occurs in the absence of testes [50]. Comparatively, the protective effect of testosterone observed in the presence of testes in the study by Albayrak et al. [50] was similar to the finding of this study in female rats.

Although the mechanism by which pretreatment with testosterone resulted in the protection of gastric damage by indomethacin is not studied, it may however be that it interferes with the mechanism by which indomethacin caused damage to the stomach. It may be that testosterone stimulates gastric prostaglandin E2 (PGE2) and prostaglandin I2 (PGI2) considering the observed inhibition of gastric acidity in this study. Recall that indomethacin inhibits PGE2 and PGI2 that are the main inhibitors of gastric acid secretion [7]. Thus, our assertion that testosterone may stimulate PGE2 and PGI2 is in line with considering the restoration of gastric acid to that of the control by pretreatment with testosterone in the present study (Figure 2). In another line of thought, the $21.74 \%$ ulcer inhibition by testosterone pretreatment in the present study suggests testosterone may inhibit gastric tissue 
damage induced by indomethacin via coupling oxidative phosphorylation and potentiating the ability of epidermal growth factor (EGF) or stimulating EGF signalling pathways to promote epithelial repair. This assertion is based on the facts that NSAIDs, for example, indomethacin, induced death of the epithelial cell by reduction of EGF, which promote epithelial repair and proliferation [10], or inhibition of EGF signalling pathways [11, 12] and/or uncoupling of oxidative phosphorylation [9].

In this regard, pretreatment with testosterone in female may be gastroprotective against indomethacin challenge via stimulating gastric prostaglandin E2 (PGE2) and prostaglandin I2 (PGI2) or acting on EGF signalling pathways to promote production or uncoupling of oxidative phosphorylation. Although weak, the findings suggest that testosterone might protect the gastric mucosa against NSAIDs in females. Conclusively, judging by the ulcer inhibition capacity exhibited by pretreatment with testosterone on indomethacin induced gastric ulcer, coupled with the potentials in maintaining mucus $\mathrm{pH}$ in comparison with the control, testosterone treatment or hormonal therapy may be promising in the management of ulcer in females. Its ability in reducing mucus content is inquisitorial and thus further studies are required. The need to further investigate the effect of testosterone in ovariectomy to eliminate the effect of female hormones in the findings of the present study is recommended.

\section{Limitation of Study}

This study did not consider the effect of testosterone acting alone on gastric integrity in nonulcer rat, or the effect of ovariectomy in female rats treated with testosterone and indomethacin, and did not put the phase of the estrous cycle of the female rats into consideration. However, the female rats used in this study were nonpregnant and where not in contact with male rats at least 28 days before the study commenced.

\section{Competing Interests}

The authors declare that there is no conflict of interests regarding the publication of this paper.

\section{References}

[1] P. C. Konturek, J. W. Konturek, and S. J. Konturek, "Gastric secretion and the pathogenesis of peptic ulcer in the Helicobacter pylori infection," Journal of Physiology and Pharmacology, vol. 47, no. 1, pp. 5-19, 1996.

[2] K. E. L. McColl, E. M. El-Omar, and D. Gillen, "The role of H. Pylori infection in the pathophysiology of duodenal ulcer disease," Journal of Physiology and Pharmacology, vol. 48, no. 3, pp. 287-295, 1997.

[3] M. Khazaei and H. Salehi, "Protective effect of Falcaria vulgaris extract on ethanol induced gastric ulcer in rat," Iranian Journal of Pharmacology and Therapeutics, vol. 5, no. 1, pp. 43-46, 2006.

[4] J. W. Kim, "NSAID-induced gastroenteropathy," Korean Journal of Gastroenterology, vol. 52, no. 3, pp. 134-141, 2008.

[5] A. Allen, G. Flemström, A. Garner, and E. Kivilaakso, "Gastroduodenal mucosal protection," Physiological Reviews, vol. 73, no. 4, pp. 823-857, 1993.
[6] A. Tarnawski, T. Brzozowski, I. J. Sarfeh et al., "Prostaglandin protection of human isolated gastric glands against indomethacin and ethanol injury. Evidence for direct cellular action of prostaglandin," Journal of Clinical Investigation, vol. 81, no. 4, pp. 1081-1089, 1988.

[7] A. C. Ribeiro-Rama, I. V. Figueiredo, F. Veiga, M. M. CastelBranco, A. M. S. Cabrita, and M. M. Caramona, "Evaluation of gastric toxicity of indomethacin acid, salt form and complexed forms with hydroxypropyl- $\beta$-cyclodextrin on Wistar rats: histopathologic analysis," Fundamental and Clinical Pharmacology, vol. 23, no. 6, pp. 747-755, 2009.

[8] R. T. Schoen and R. J. Vender, "Mechanisms of nonsteroidal anti-inflammatory drug-induced gastric damage," The American Journal of Medicine, vol. 86, pp. 449-458, 1989.

[9] S. Somasundaram, H. Hayllar, S. Rafi, J. M. Wrigglesworth, A. J. S. Macpherson, and I. Bjarnason, "Review: the biochemical basis of non-steroidal anti-inflammatory drug-induced damage to the gastrointestinal tract: a review and a hypothesis," Scandinavian Journal of Gastroenterology, vol. 30, no. 4, pp. 289-299, 1995.

[10] Y. Fujiwara, A. Schmassmann, T. Arakawa, F. Halter, and A. Tarnawski, "Indomethacin interferes with epidermal growth factor binding and proliferative response of gastric KATO III cells," Digestion, vol. 56, no. 5, pp. 364-369, 1995.

[11] R. Kajanne, S. Leppä, P. Luukkainen et al., "Hydrocortisone and indomethacin negatively modulate EGF-R signaling in human fetal intestine," Pediatric Research, vol. 62, no. 5, pp. 570-575, 2007.

[12] R. Pai, I. L. Szabo, A. Q. Giap, H. Kawanaka, and A. S. Tarnawski, "Nonsteroidal anti-inflammatory drugs inhibit reepithelialization of wounded gastric monolayers by interfering with actin, Src, FAK, and tensin signaling," Life Sciences, vol. 69, no. 25-26, pp. 3055-3071, 2001.

[13] T. Garrick, F. W. Leung, S. Buack, K. Hirabayashi, and P. H. Guth, "Gastric motility is stimulated but overall blood flow is unaffected during cold restraint in the rat," Gastroenterology, vol. 91, no. 1, pp. 141-148, 1986.

[14] M. G. Repetto and S. F. Llesuy, "Antioxidant properties of natural compounds used in popular medicine for gastric ulcers," Brazilian Journal of Medical and Biological Research, vol. 35, no. 5, pp. 523-534, 2002.

[15] Z. P. Lima, J. A. Severi, C. H. Pellizzon et al., "Can the aqueous decoction of mango flowers be used as an antiulcer agent?" Journal of Ethnopharmacology, vol. 106, no. 1, pp. 29-37, 2006.

[16] K. E. L. McColl, E. M. El-Omar, and D. Gillen, "The role of H. pylori infection in the pathophysiology of duodenal ulcer disease," Journal of Physiology and Pharmacology, vol. 47, pp. 519, 1996.

[17] O. S. Malyshenko, E. I. Beloborodova, A. L. Vavilov, G. V. Lomivorotova, and V. I. Kasperskaya, "Impact of age and type of behavior on the course of ulcer disease," Terapevticheskii Arkhiv, vol. 77, no. 2, pp. 28-31, 2005.

[18] J. W. Kim, "NSAID-induced gastroenterpathy," The Korean Journal of Gastroenterology, vol. 52, no. 3, pp. 134-141, 2008.

[19] M. Bagchi, M. Milnes, C. Williams et al., "Acute and chronic stress-induced oxidative gastrointestinal injury in rats, and the protective ability of a novel grape seed proanthocyanidin extract," Nutrition Research, vol. 19, no. 8, pp. 1189-1199, 1999.

[20] U. Bandyopadhyay, D. Das, D. Bandyopadhyay, M. Bhattacharjee, and R. K. Banerjee, "Role of reactive oxygen species in mercapto-methylimidazole-induced gastric acid secretion and 
stress-induced gastric ulceration," Current Science, vol. 76, no. 1, pp. 55-63, 1999.

[21] S. M. K. Rates, "Plants as source of drugs," Toxicon, vol. 39, no. 5, pp. 603-613, 2001.

[22] B. Cherqui, B. Desaint, C. Legendre, and V. G. Levy, "Fatal hepatitis associated with ranitidine," Gastroenterologie Clinique et Biologique, vol. 13, no. 11, pp. 952-953, 1989.

[23] J. M. Ribeiro, M. Lucas, A. Baptista, and R. M. M. Victorino, "Fatal hepatitis associated with ranitidine," American Journal of Gastroenterology, vol. 95, no. 2, pp. 559-560, 2000.

[24] A. Chaturvedi, M. Mohan Kumar, G. Bhawani, H. Chaturvedi, M. Kumar, and R. K. Goel, "Effect of ethanolic extract of Eugenia jambolana seeds on gastric ulceration and secretion in rats," Indian Journal of Physiology and Pharmacology, vol. 51, no. 2, pp. 131-140, 2007.

[25] I. Z. A. Abdallah, H. A. H. Khattaba, and G. H. Heebab, "Gastroprotective effect of Cordia myxa L. fruit extract against indomethacin-induced gastric ulceration in rats," Life Science Journal, vol. 8, no. 3, pp. 433-445, 2011.

[26] A. Machowska, A. Szlachcic, M. Pawlik, T. Brzozowski, S. J. Konturek, and W. W. Pawlik, "The role of female and male sex hormones in the healing process of preexisting lingual and gastric ulcerations," Journal of Physiology and Pharmacology, vol. 55, no. 2, pp. 91-104, 2004.

[27] I. Y. Ibrahim, M. S. Abdel-Hakim, K. M. Hassan, and A. E. El-Bassioni, "Influence of gender difference on cold restraint gastric ulcer development in albino rats," El-Minia Medical Bulletin, vol. 16, no. 1, pp. 365-382, 2005.

[28] B. J. Kirsner, "Hormones and peptic ulcer," Bulletin of the New York Academy of Medicine, vol. 29, no. 6, pp. 477-504, 1953.

[29] W. H. Hall, "Breast changes in males on cimetidine," New England Journal of Medicine, vol. 295, no. 15, p. 841, 1976.

[30] D. H. Van Thiel, J. S. Gavaler, W. I. Smith Jr., and G. Paul, "Hypothalamic-pituitary-gonadal dysfunction in men using cimetidine," The New England Journal of Medicine, vol. 300, no. 18, pp. 1012-1015, 1979.

[31] S. J. Winters, J. L. Banks, and D. L. Loriaux, "Cimetidine is an antiandrogen in the rat," Gastroenterology, vol. 76, no. 3, pp. 504-508, 1979.

[32] S. Tosi and M. Cagnoli, "Painful gynecomastia with ranitidine (letter)," The Lancet, vol. 8290, p. 160, 1982.

[33] C. R. W. Edwards and A. J. Riley, "Endocrine effects of ranitidine: comparison with cimetidine," in Proceedings of the $2 n d$ International Symposium on Ranitidine, J. Misiewicz and K. G. Wormsely, Eds., Medicine Publishing Foundation, Oxford, UK, 1982.

[34] U. Akpamu, V. B. Owoyele, M. Ozor, and U. C. Osifo, "Indomethacin-induced gastric ulcer: model in female Wistar rats," International Journal of Basic, Applied and Innovative Research, vol. 2, no. 4, pp. 78-84, 2013.

[35] M. A. Abdulla, K. A.-A. Ahmed, F. H. Al-Bayaty, and Y. Masood, "Gastroprotective effect of Phyllanthus niruri leaf extract against ethanol-induced gastric mucosal injury in rats," African Journal of Pharmacy and Pharmacology, vol. 4, no. 5, pp. 226230, 2010.

[36] K. A. Ketuly, M. A. Abdulla, H. A. Hadi, A. A. Mariod, and S. I. Abdel-Wahab, "Anti ulcer activity of the 9 alpha-bromo analogue of Beclomethasone dipropionate against ethanol-induced gastric mucosal injury in rats," Journal of Medicinal Plants Research, vol. 5, no. 4, pp. 514-520, 2011.
[37] G. Wilhelmi and R. Menasse-Gdynia, "Gastric mucosal damage induced by non-steroid anti-inflammatory agents in rats of different ages," Pharmacology, vol. 8, pp. 321-328, 1972.

[38] J. Hano, J. Bugajski, and L. Danek, "Effect of adrenergic blockade on gastric secretion altered by catecholamines in rats," Archivum Immunologiae et Therapiae Experimentalis, vol. 24, no. 4, pp. 507-524, 1976.

[39] A. El-Tawil, "Gender and the pathogenesis of gastrointestinal diseases: the role of steroid sex hormones in the development," Journal of Steroids \& Hormonal Science, vol. 2, article e101, 2011.

[40] L. Limlomwongse and P. Piyachaturawat, "Inhibition of gastric $\mathrm{H}^{+}$secretion, $\mathrm{K}^{+}$-ATPase and $\mathrm{K}^{+}$-phosphatase by estradiol in vivo and in vitro," Canadian Journal of Physiology and Pharmacology, vol. 60, no. 5, pp. 680-684, 1982.

[41] C. N. Aguwa, "Effects of exogenous administration of female sex hormones on gastric secretion and ulcer formation in the rat," European Journal of Pharmacology, vol. 104, no. 1-2, pp. 79-84, 1984.

[42] K. O. Adeniyi, "Gastric acid secretion and parietal cell mass: effect of sex hormones," Gastroenterology, vol. 101, no. 1, pp. 6669, 1991.

[43] T. Sakaguchi, M. Yamazaki, S. Itoh, N. Okamura, and T. Bando, "Gastric acid secretion controlled by oestrogen in women," Journal of International Medical Research, vol. 19, no. 5, pp. 384388, 1991.

[44] K. Girma, I. Janczewska, B. Romell et al., "Twenty-four-hour basal and repetitive pentagastrin-stimulated gastric acid secretion in normal and sham-operated rats and in rats after gonadectomy or treatment with estradiol or testosterone," Scandinavian Journal of Gastroenterology, vol. 32, no. 7, pp. 669-675, 1997.

[45] P. C. MacDonald, R. P. Rombaut, and P. K. Siiteri, "Plasma precursors of estrogens. I. Extent of conversion conversion of plasma $\Delta^{4}$-androstenedione to estrone in normal males and nonpregnant normal, castrate and adrenalectomized females," The Journal of Clinical Endocrinology \& Metabolism, vol. 27, no. 8, 1967.

[46] C. D. West, B. L. Damast, S. D. Sarro, and H. O. Pearson, "Conversion of testosterone to estrogens in castrated, adrenalectomized human females," The Journal of Biological Chemistry, vol. 218, no. 1, pp. 409-418, 1956.

[47] R. B. Leach, W. O. Maddock, C. A. Paulsen, and I. Tokuyama, "Clinical studies of testicular hormone production," Recent Progress in Hormone Research, vol. 12, pp. 377-403, 1956.

[48] F. Laszlo, E. Amani, C. Varga, and F. A. Laszlo, "Influence of sex hormones on ethanol-induced gastric haemorrhagic erosions in rats," Acta Physiologica Hungarica, vol. 80, no. 1-4, pp. 289-292, 1992.

[49] F. László, C. Varga, C. Montoneri, and F. Drago, "Damaging actions of testosterone on cysteamine-induced gastroduodenal ulceration and vascular leakage in the rat," European Journal of Pharmacology, vol. 337, no. 2-3, pp. 275-278, 1997.

[50] Y. Albayrak, Z. Halici, F. Odabasoglu et al., "The effects of testosterone on intestinal ischemia/reperfusion in rats," Journal of Investigative Surgery, vol. 24, no. 6, pp. 283-291, 2011. 


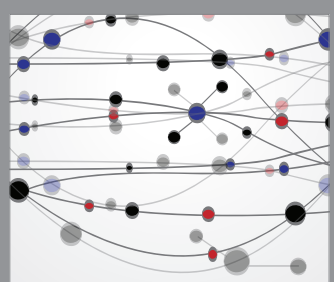

The Scientific World Journal
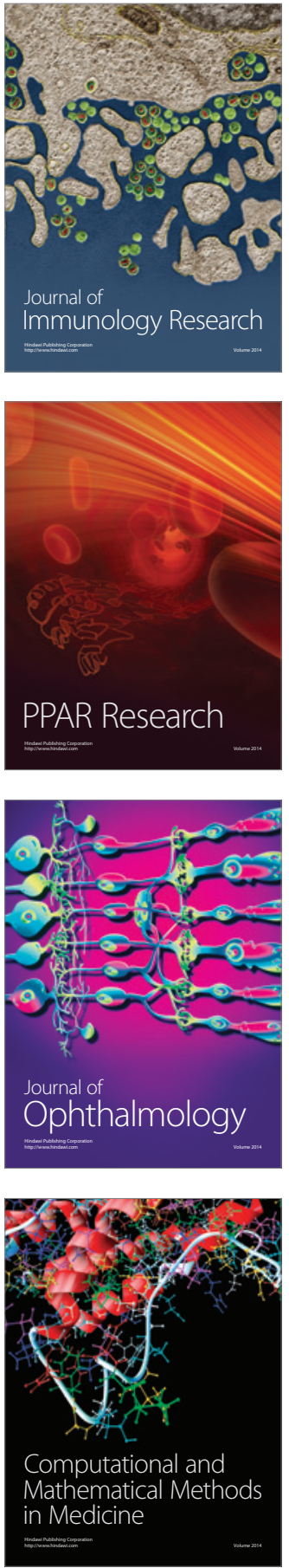

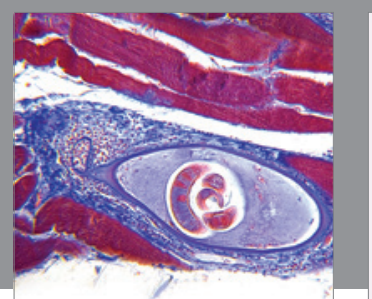

Gastroenterology Research and Practice

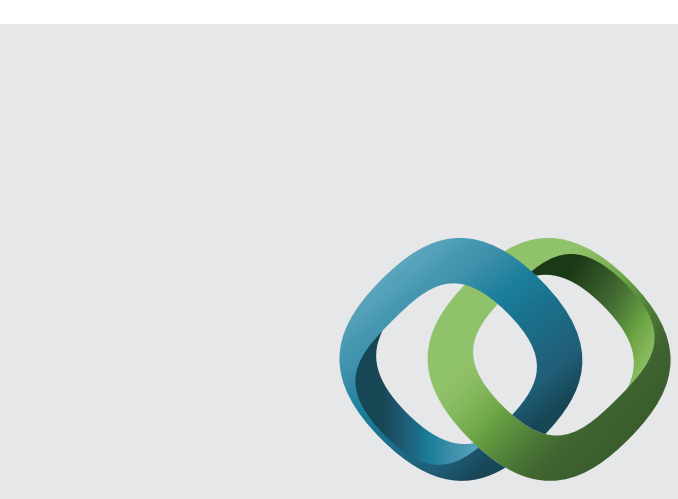

\section{Hindawi}

Submit your manuscripts at

http://www.hindawi.com
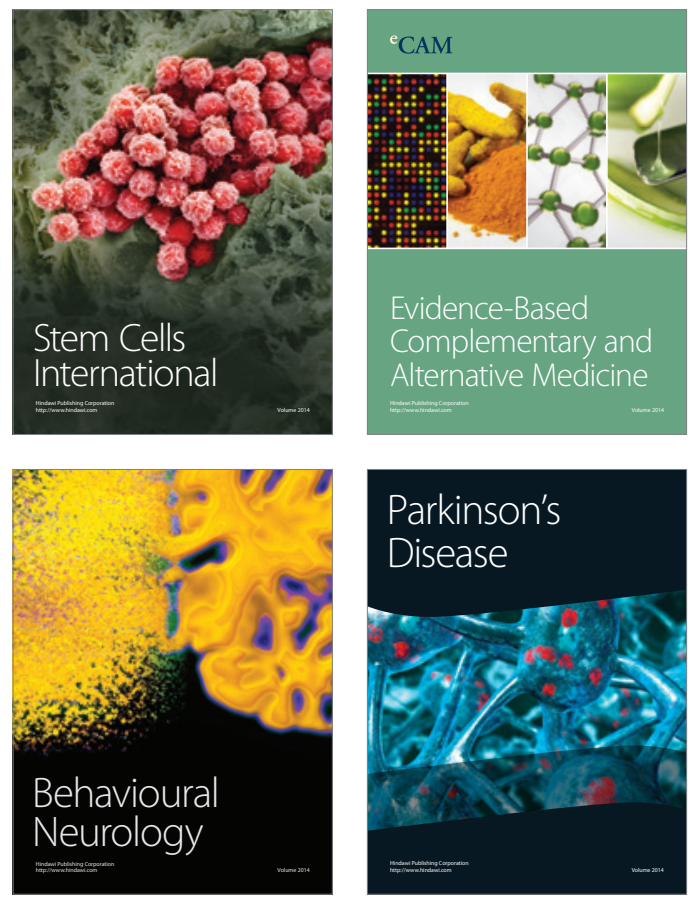
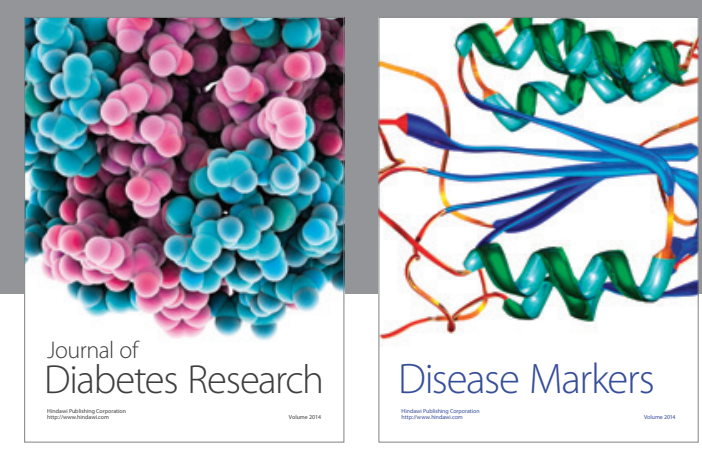

Disease Markers
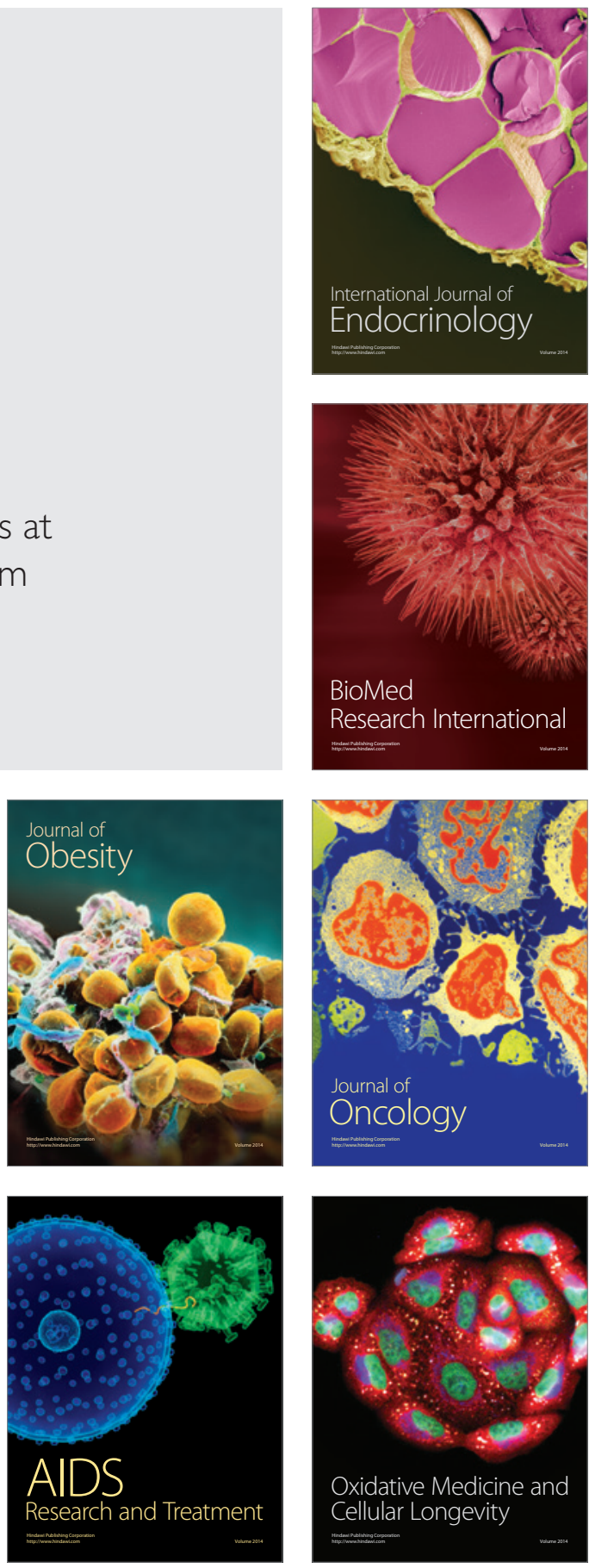